\title{
Deep brain stimulation (DBS) at the interface of neurology and psychiatry
}

\author{
Nolan R. Williams ${ }^{1,2}$ and Michael S. Okun ${ }^{3,4,5}$ \\ ${ }^{1}$ Department of Psychiatry and 2Department of Neurosciences, Medical University of South Carolina, Charleston, South Carolina, USA. \\ ${ }^{3}$ Department of Neurology, ${ }^{4}$ Department of Neurosurgery, and ${ }^{5}$ Department of Psychiatry, \\ University of Florida Center for Movement Disorders and Neurorestoration, Gainesville, Florida, USA.
}

\begin{abstract}
Deep brain stimulation (DBS) is an emerging interventional therapy for well-screened patients with specific treatment-resistant neuropsychiatric diseases. Some neuropsychiatric conditions, such as Parkinson disease, have available and reasonable guideline and efficacy data, while other conditions, such as major depressive disorder and Tourette syndrome, have more limited, but promising results. This review summarizes both the efficacy and the neuroanatomical targets for DBS in four common neuropsychiatric conditions: Parkinson disease, Tourette syndrome, major depressive disorder, and obsessive-compulsive disorder. Based on emerging new research, we summarize novel approaches to optimization of stimulation for each neuropsychiatric disease and we review the potential positive and negative effects that may be observed following DBS. Finally, we summarize the likely future innovations in the field of electrical neural-network modulation.
\end{abstract}

\section{Introduction}

Deep brain stimulation (DBS) is a technique that consists of a surgically implanted lead that provides focal electrical neural-network modulation within a brain circuit or circuits of interest. Initially, modern DBS systems were developed to address dysfunctional circuits in patients diagnosed with treatment-resistant tremor or other movement disorders; recently, DBS's therapeutic role has expanded to several neuropsychiatric disorders. Neuropsychiatry is an evolving branch of medicine dealing with diseases in which the affected have symptoms that are both "neurologic" and "psychiatric" (1). The expansion of disease-specific indications has allowed scientists to move beyond traditional movement-related circuitry in order to address these relevant neuropsychiatric issues such as treatmentresistant mood and cognitive symptoms (2).

Diseases and indications with more concrete targets and straightforward outcomes, such as essential tremor, motoric symptoms of Parkinson disease (PD), and motor symptoms of dystonia, have been the most studied to date. The US FDA issued an approval for the use of DBS in essential tremor in 1997 and PD in 2002. A humanitarian device exemption (HDE) was granted for motoric symptoms of dystonia in 2003 (3). More complex cognitive and limbic targets, such as obsessivecompulsive disorder (OCD), depression, and Tourette syndrome (TS), have proven more difficult to study (2). The US FDA issued a HDE for obsessive compulsive disorder in 2009 (4). TS and depression both remain unapproved uses of DBS technology; however, many groups are implanting these patients under research protocols.

This review will focus on DBS in four neuropsychiatric syndromes: PD, TS, major depressive disorder (MDD), and OCD. Each disease has multiple brain targets (Figure 1), and each of the targets has been demonstrated as promising, albeit with reported unintended negative and positive effects. Following a brief review of the implantation/programming process, we will summarize the advances in optimized targeting and stimulation parameters. We will then discuss the four neuropsychiatric diseases, the

Conflict of interest: The authors have declared that no conflict of interest exists. Citation for this article: J Clin Invest. 2013;123(11):4546-4556. doi:10.1172/JCI68341. currently utilized brain targets for each disease, and both the neuropsychiatric and motoric effects of the intervention. Finally, we will conclude with a description of other potential advances and pitfalls in this promising area (5).

\section{DBS placement and programming}

Preimplantation. Several variables should be considered prior to performing DBS surgery for a neuropsychiatric indication. Demonstration of treatment resistance (failure of both pharmacological and nonpharmacological interventions) is critical for all potential candidates $(6,7)$. The definitions for "treatment resistance" have been clearly defined for some (8-10), but not all neuropsychiatric conditions (11). There are DBS inclusion and exclusion criteria published for TS (12) and PD (13); however, there are less welldefined guidelines for depression and OCD (14). In the case of MDD and OCD, treatment resistance has been defined as the failure of standard of care interventions such as antidepressants and adjunctive medications (see STAR*D) (15), and psychotherapy (typically cognitive behavioral therapy [CBT]) as well as electroconvulsive therapy and/or transcranial magnetic stimulation in the case of MDD (16). Further, patients should be screened for comorbid psychiatric disease, as certain conditions predispose patients to worse DBS outcomes $(17,18)$. Moreover, clinicians should ensure that patients do not exhibit any clinically significant or unstable neurological medical illnesses and assess the patient for the capacity to understand the potential for harm as well as any therapeutic misconceptions.

Implantation. DBS implantation involves the use of stereotactic neurosurgical technique and modern imaging, which together allow for the treatment team to directly target a node in a dysfunctional circuit of interest. Next, microelectrode mapping (if performed) and intraoperative macro- or test stimulation occurs. In the case of PD, the tremor or rigidity and bradykinesia typically respond to intraoperative stimulation $(19,20)$, and this may aid in selecting the final target. In depression or OCD, for a few reported cases, intraoperative stimulation has been shown to result in subjective feelings of calmness, improved mood, and increased interest/motivation during macrostimulation in the sub- 


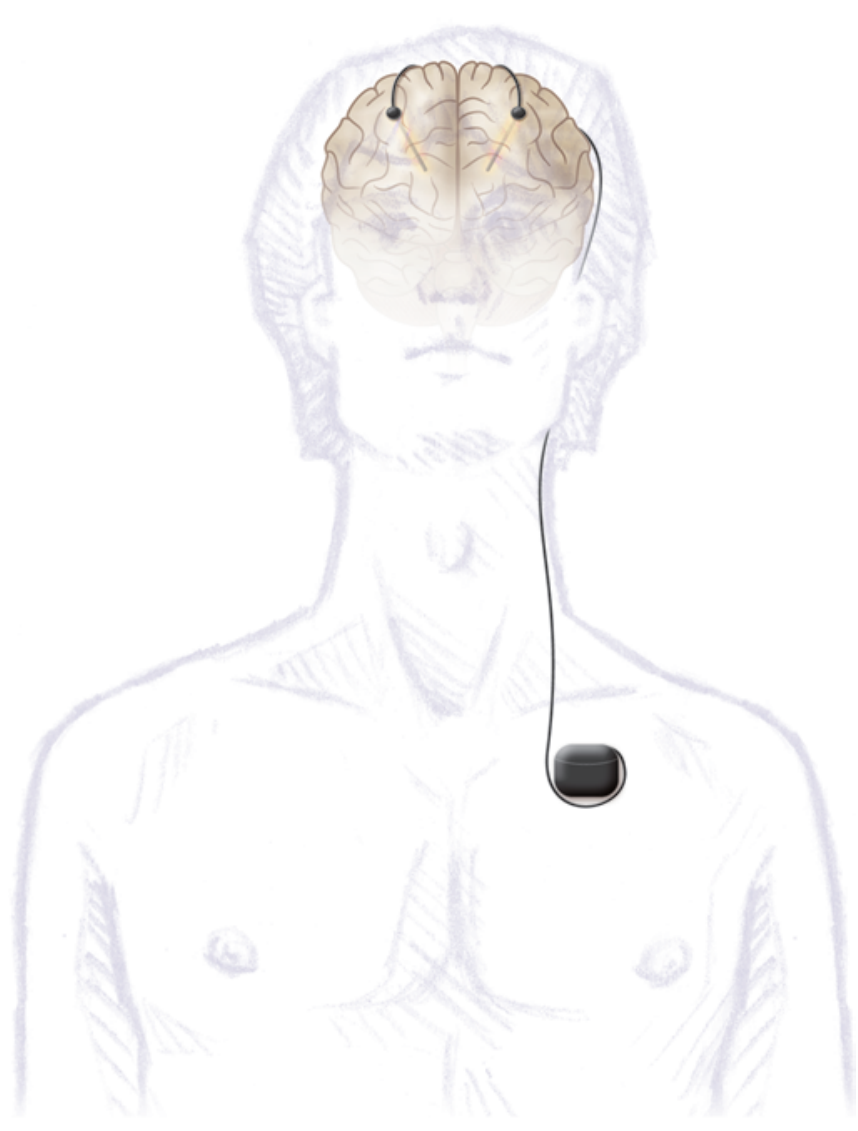

\section{Figure 1}

The modern version of the DBS system includes an electrode implanted into a deep brain target, which has been postulated to function as an important node that possesses the potential to modulate a dysfunctional brain circuit. The DBS lead is connected through an extension wire to an IPG (i.e., battery, neurostimulator), which is placed in the chest under the clavicle, or, less frequently, in the abdomen. The system is telemetrically programmed through the use of an external programming device to deliver pulses of electricity into the target region. These electrical pulses can modulate a circuit of interest to relieve disease symptoms. Schematic is not anatomically accurate.

callosal cingulate (SCC) target (21). Similarly, a contralateral smile and feelings of euphoria have been observed when stimulating in the ventral capsule/ventral striatum (VC/VS) (22). The presence of intraoperative stimulation effects such as the contralateral smile after stimulation in the ventral striatum has been demonstrated to predict eventual response to therapy (23). Once mapping is complete, a patient then receives a battery (implantable pulse generator [IPG]) placement within the next one to two weeks (24).

$D B S$ programming. DBS programming typically occurs approximately two to four weeks after DBS surgery, with the delay due to the lead placement itself causing a transient improvement in symptoms through a "microlesion effect" (25). Programming involves the use of a handheld machine that communicates wirelessly with the chest, or with the abdominal-based neurostimulator (i.e., battery source) (Figure 2). The objective of the initial programming session is to set and fine-tune stimulation parameters. There are several programming variables that must be set, such as the electrode polarity, amplitude, pulse width, and frequency. The optimal DBS settings may depend on the disease, the targeted symptoms, and the neuroanatomical location of the stimulation field within the desired target (26). Research protocols have also been enhanced by programming "sham-DBS settings" to overcome the placebo effect of psychiatric outcomes within neurosurgery (27). Concomitant medication changes may also be required. The general lack of immediate feedback (i.e., clinical improvement in the office) in DBS programming for psychiatric diseases increases the level of difficulty and generally renders programming complex. Some of the challenge can be overcome through use of standardized self-rated and observer-rated instruments (26).

Some programming-related observations may be important predictors of chronic efficacy (21); however, no definitive immediate programming-related biomarkers have been validated. In neuropsychiatric diseases such as depression and OCD, satisfactory results can take as long as four to six months to achieve. Recent advances in target selection may reduce this latency to days in the case of depression (28). There is a risk of device malfunction (29), and in all cases, neurostimulator replacement may be necessary (30), provided the DBS patient outlives the device (i.e., typically two to five years for device replacement and seven to ten years for rechargeable batteries).

\section{Novel methods of DBS optimization}

DBS is evolving into a field of personalized medicine (31), with practitioners increasingly prescribing therapy for constellations of symptoms and making customized modifications to optimize symptoms (32). Because of the microstructural variability within an individual's brain connectivity (33), personalization of therapy will likely occur not only at the level of modifications for specific disease and general affected circuitry (34), but potentially even at the level of an individual's differences in specific neural connections (35). The use of diffusion tractography alongside traditional landmark-based targeting techniques for implantation of DBS electrodes may offer the level of imaging support necessary to start this personalized microstructural mapping (36). This technique could allow derivation of individual tractography maps that may aid in defining patterns of connectivity that could potentially optimize electrode placement and therefore individualize therapy (37). Optogenetics is another powerful technique for probing the pathways potentially responsible for neuropsychiatric disease while leaving the surrounding neural circuitry untouched (38). It has already been used to demonstrate that the therapeutic effects of DBS within the subthalamic nucleus (STN) for PD can be accounted for by stimulation of the afferent axons projecting to the STN (38).

Modifications of stimulation parameters, such as change in the geometry of the waveform, have been shown to have marked effects on charge and energy requirements (39). While fixed compliance voltage for constant-current stimulation has been shown to result in substantial energy loss, some of this energy can be recuperated if the compliance voltage can be adjusted in real time (40). The utilization of constant-current devices coupled with current steering programming strategies where multiple cathodes are used to modify the field can further optimize stimulation (41). Energy optimization can also be improved through the computation of an individual's axon fiber diameter to determine pulse width (40). Exploration of more target-specific electrodes could potentially optimize delivery through novel interactions with the circuitry of interest (42). 
Recent reports indicate that neural oscillations could potentially be used to guide DBS programming, particularly in the absence of noticeable changes in clinical symptoms. Several groups have been working to use these local field potentials to develop biomarkers of efficacy such that a closed loop system can be developed. The use of the $\beta$ band for PD (43), the $\theta$ band for depression in thesubcallosal cingulate (44), and the $\gamma$ band for TS (45) in the centromedian nucleus of the thalamus (CM) may prove to be useful. Several groups are currently using a closed-loop device to record and then stimulate on demand (46). The intent in all of these explorations is the development of a marker that can be adjusted in real time. This technology has already become available in epilepsy devices where the electrical signature is better characterized (47).

\section{Neuropsychiatric disease and DBS targets}

$P D . P D$ is a neurodegenerative syndrome that affects motor and nonmotor thalamocortical circuitry within the parallel and segregated basal ganglia system. PD-related neurodegeneration results in characteristic changes in neuronal firing rates, firing patterns (48), and also in oscillatory brain-cell activity (43). Many of these changes are believed to manifest clinically as tremor, rigidity, bradykinesia, apathy, depression, and/or cognitive dysfunction (49). Several randomized clinical trials in PD have revealed efficacy in both unilateral and bilateral STN and/or globus pallidus pars internus (GPi) DBS. In many of the trials, results have directly compared outcomes of DBS and traditional medical management (see Table 1). In 2006, Deuschl and colleagues demonstrated that STN DBS was superior to medication management in advanced PD (50), results that were corroborated in the 2010 PD SURG trial (51) and in a younger, less advanced PD group in 2013 (52).

Because of the uncertainty of both the efficacy and the side effects from STN DBS and GPi DBS, several studies were conducted to compare GPi and STN. In 2009, the NIH COMPARE trial demonstrated no significant differences in mood or cognition when in the optimal DBS state, while simultaneously demonstrating equal motor outcomes in the two targets. Worsened verbal fluency was demonstrated, however, when the STN target was in one of three nonoptimal DBS states (53). In 2010, Follett also demonstrated that GPi and STN had equal motor efficacy at 24 months (54), but a follow-up study revealed more long-term cognitive problems in the STN group (55). STN is likely to be the preferred target for PD DBS if medication reduction is desired (56), while GPi is likely the best choice if dyskinesia and/or preexisting cognitive issues are present (refs. 32, 53, and 57; also see Table 1).

In order to more fully explain the mechanisms that underlie the therapeutic efficacy of DBS for PD, efforts to model the pathophysiologic mechanisms of PD will ideally link abnormal basal ganglia activity to the cardinal parkinsonian motor signs (58). Computational approaches have the potential to play an important role in exploring these mechanisms (58). Currently, clinicians are utilizing methods to reduce side effects, particularly mood and cognitive alterations, through the optimization of lead placement within the target (59). Future improvements may include customized modification of the electrode trajectory (60) and placement along with clinical stimulation parameter settings using a patient-specific model and atlas (PSA) (61-63). The use of temporally nonregular stimulation parameters may also allow for further honing of the therapy in an effort to increase battery life and to improve network delivery (64).
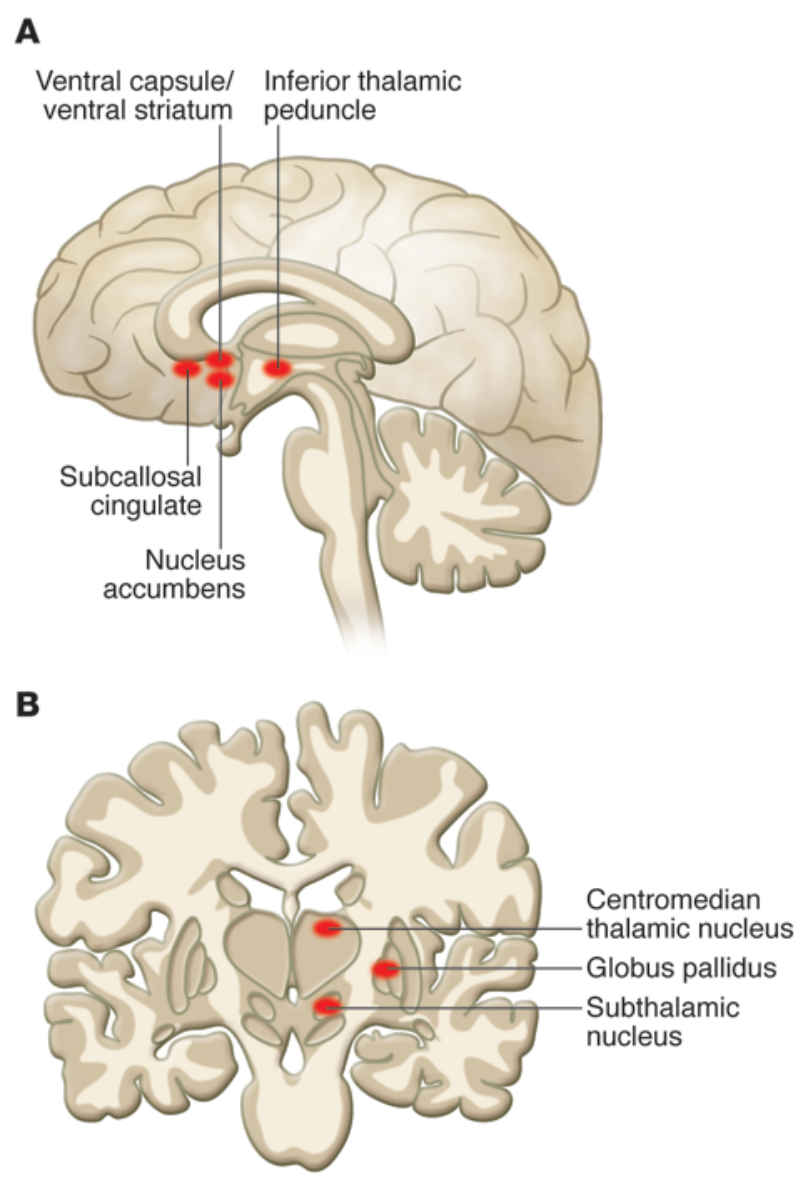

Figure 2

General schematic of DBS targets. (A) Sagittal view of DBS targets including VC/VS, STN, SCC, and ITP. (B) Coronal view of DBS targets including STN, GPi, and CM. Schematic is not anatomically accurate.

TS. TS is an early life-onset neuropsychiatric condition affecting approximately $1 \%$ of individuals worldwide. TS is characterized by multiple motor tics and one or more vocal tics that persist for more than a year. Approximately $90 \%$ of sufferers have comorbid disorders, including attention-deficit/hyperactivity disorder (ADHD), OCD, and self-injurious behaviors (SIB). In severe adult TS cases, DBS has been used in disabling settings when the patient is both medication and behavioral intervention resistant (65). There are multiple TS targets including the CM and substantia periventricularis (SPV) (66), the posteroventral (PV) GPi, the ventromedial (VM) GPi, the globus pallidus externus (GPe) (67), the STN (68), and the anterior limb of the internal capsule/nucleus accumbens (ALIC/NAc) region (69). We will discuss the two targets that have been the best characterized, and most utilized in clinical practice, the GPi (both the PV motor and VM nonmotor regions) and the $\mathrm{CM}$. There are no large randomized controlled studies comparing TS targets available (69).

The largest study to date utilized the CM thalamus and demonstrated an average 52\% reduction in Yale Global Tic Severity Scores (YGTSS) (65). The effect appeared to be reasonably durable: the long-term follow-up demonstrated 17 of 18 subjects had a $30 \%$ or greater reduction in their YGTSS (70). Of note, the CM target 


\section{Table 1}

Summary of studies of PD DBS, both DBS versus medical management and GPi DBS versus STN DBS

\begin{tabular}{|c|c|c|c|c|c|}
\hline Study & No. patients & Target & $\mathrm{F} / \mathrm{u}$ & Outcome Positive effects & Outcome Negative effects \\
\hline Deuschl 2006 (ref. 50) & 156 & STN & $6 \mathrm{mo}$ & $\begin{array}{l}\text { Significant PD symptom improvement } \\
\text { and decrease of levadopa use }\end{array}$ & $\begin{array}{l}\text { Weight gain } \\
\text { and worsening of dyskinesias }\end{array}$ \\
\hline Okun 2012 (ref. 165) & 168 & STN & $3 \mathrm{mo}$ & $\begin{array}{l}\text { Significant PD symptom improvement } \\
\text { and decrease of levadopa use }\end{array}$ & Dysarthria, depression, fatigue \\
\hline Schuepbach 2013 (ref. 52) & 251 & STN & $24 \mathrm{mo}$ & $\begin{array}{l}\text { Significant PD symptom improvement } \\
\text { and decrease of levadopa use }\end{array}$ & $\begin{array}{l}\text { Impulse control worsening, } \\
\text { depression, suicide attempt }\end{array}$ \\
\hline Okun 2009 (ref. 53) & 52 & $\begin{array}{l}23 \mathrm{GPi}, \\
22 \mathrm{STN}\end{array}$ & $7 \mathrm{mo}$ & Significant PD symptom improvement & $\begin{array}{l}\text { Significant decrease in verbal } \\
\text { fluency and increase in anger }\end{array}$ \\
\hline Williams 2010 (ref. 51) & 183 & STN or GPi & $12 \mathrm{mo}$ & Significant PD symptom improvement & Psychosis, anxiety, suicide \\
\hline Follett 2010 (ref. 54) & 299 & $\begin{array}{l}152 \mathrm{GPi}, \\
147 \mathrm{STN}\end{array}$ & $24 \mathrm{mo}$ & $\begin{array}{l}\text { Significant PD symptom improvement } \\
\text { and decrease of levadopa use }\end{array}$ & $\begin{array}{l}\text { Slight decrease in } \\
\text { memory function, NS }\end{array}$ \\
\hline Odekerken 2012 (ref. 166) & 128 & $\begin{array}{l}65 \mathrm{GPi}, \\
63 \mathrm{STN}\end{array}$ & $12 \mathrm{mo}$ & $\begin{array}{l}\text { Significant PD symptom improvement } \\
\text { and decrease of levadopa use }\end{array}$ & $\begin{array}{l}\text { Slight increase in } \\
\text { dementia score, NS }\end{array}$ \\
\hline
\end{tabular}

F/u, follow-up.

appeared to have effects on OCD, depression, and anxiety symptoms, with an average reduction of 9 points on the Yale-Brown Obsessive Compulsive Scale (YBOCS) (42\% reduction in the score), a reduction of 17 points on the Beck Depression Inventory (BDI) (55\% reduction in the score), and an approximately 20 -point reduction in the State-Trait Anxiety Inventory (STAI) (54\% reduction in the score) (70). Two other smaller CM DBS studies demonstrated similar improvements $(71,72)$. For the GPi target, Martinez-Fernandez and colleagues demonstrated an average reduction of approximately $30 \%$ in the YGTSS (73). In a more recent study, 10 of 11 patients reported improvement in tic severity with an overall $48 \%$ reduction in motor tics and a $56.5 \%$ reduction in phonic tics at final follow-up. Six patients $(54.5 \%)$ had a more than $50 \%$ reduction (ref. 74 and see Table 2 ). Additionally, the nonmotor target, NAc, has been explored for TS and surprisingly has demonstrated improvements in TS motor symptoms (69).

There are many unanswered questions in TS DBS. Does the altered connectivity in TS (75) explain the apparent improvements in motor tics after stimulation of a "limbic" target (NAc DBS) (76)? Which subcomponent of the GPi should be targeted (73)? Advances in the treatment of TS could involve a head-to-head comparison of major targets (such as the GPi versus $\mathrm{CM}$ versus NAc) in order to determine not only which of the targets has the greatest efficacy in reducing motor tics, but additionally which one has the greatest efficacy in reducing the comorbid psychiatric symptoms (77). Only one study has attempted to answer this question, and it demonstrated superiority of GPi with a small number of patients (78). Future studies should determine ideal stimulation conditions (should continuous stimulation be used for a paroxysmal disorder?) (46) and characterize alterations in downstream neurotransmitter function (79). Future directions will most certainly include the use of closed-loop systems and may utilize a patient-controlled function, since tics are intermittent and the sufferer often has a premonitory urge (80). In the future, a TS patient may utilize multiple leads to treat different symptom clusters (81-83).

$M D D$. Depression is defined as a state of extreme sadness or melancholia that affects a person's activities in daily life as well as social functioning. Nearly one in five people experience an episode of major depression in their lifetime, and the World Health
Organization declared major depression one of the four most disabling illnesses worldwide (84). Currently, antidepressants and/or psychotherapy are the mainstay of treatment, along with electroconvulsive therapy, which is reserved for treatment-resistant individuals. DBS is being utilized in a research setting for patients who do not respond to conventional therapies (see Table 4).

Four main targets exist for depression DBS: the VC/VS, the subcallosal cingulate (SCC) (brain area 25 [BA 25]), the NAc, and the medial forebrain bundle (MFB) (28), although the inferior thalamic peduncle (ITP) (85) and lateral habenula (86) are also potentially efficacious DBS targets. All four of the major DBS targets for depression have been studied for treatment-resistant individuals, and all have demonstrated positive results in small series, but there are no major randomized studies comparing these targets. For MDD, the response is defined as greater than or equal to a $50 \%$ reduction in the Hamilton Depression Rating Scale score (HDRS) or Montgomery-Asberg Depression Rating Scale (MADRS), while remission is a score of "nondepressed" on HDRS or MADRS.

The SCC has been demonstrated to be an important node in the mood regulation circuitry (87) and a novel neurosurgical target for depression (21). It carries the benefit of treating both unipolar and bipolar depression (88) while appearing not to have the risk of mania seen with other depression targets (89). For SCC, an initial response rate (24-26 weeks) of $41 \%-66 \%$ has been reported, while at two to six years, the response rates increased to $64 \%-92 \%$ with remission rates of $42 \%-58 \%$ (90). In a different pooled analysis from the same group, the initial response rate at six months was $46.4 \%(16,88,91,92)$. Mood, interest, psychic anxiety, middle insomnia, and suicidality are affected by this intervention and are therefore primary contributors to the HDRS score improvement (91). The Mayberg group has demonstrated that they can isolate the exact white matter projections that interface with the active contacts of those in remission through the use of tractography methods. This method has shown that the SCC target is effective when it contacts tracts that cause downstream changes in the midline thalamus, ventral pallidum, and medial frontal cortex (93). The long-term response rate for SCC DBS was approximately $60 \%$ (94). In addition to appropriate electrode placement, programming parameters within this node have not been fully explored (95) and optimized (96). Future trials, such as the ongoing multi- 
Table 2

Summary of studies of TS DBS including CM DBS and GPi DBS

\begin{tabular}{|c|c|c|c|c|}
\hline Study & No. patients & Target & $\mathrm{F} / \mathrm{u}$ & Outcome summary \\
\hline Porta 2012 (ref. 70) & 18 & $\mathrm{CM}$ & $5-6 \mathrm{yr}$ & Tics, OCD, depression, and anxiety significantly decreased \\
\hline Ackermans 2011 (ref. 72) & 6 & $\mathrm{CM}$ & $12 \mathrm{mo}$ & $\begin{array}{l}\text { Tics significantly decreased; OCD, depression, } \\
\text { and anxiety decreased, but NS }\end{array}$ \\
\hline Maciunas 2007 (ref. 71) & 5 & $\mathrm{CM}$ & $3 \mathrm{mo}$ & Tics, OCD, depression, and anxiety decreased \\
\hline Cannon 2012 (ref. 74) & 11 & GPi & $4-30$ mo & $\begin{array}{c}10 \text { out of } 11 \text { had decreased TS symptoms, } \\
\text { but one did not tolerate DBS } \\
\text { and two had increased anxiety }\end{array}$ \\
\hline Fernandez 2011 (ref. 73) & 5 & GPi & $3-24$ mo & Tics and OCD decreased \\
\hline
\end{tabular}

site randomized control trial (BROADEN), may potentially utilize parameters described above to optimize treatment delivery.

The VC/VS target could potentially treat depression through its apparent mood effects in individuals who received this intervention for OCD. The response and remission rates of VC/VS at six months were $40 \%$ and $20 \%$, respectively (97), and $71 \%$ and $35 \%$ at last follow-up (14-67 months) (98). The long-term response rate for VC/VS DBS was approximately $71 \%$ (98). A recent large study of VC/VS DBS conducted by the Medtronic company failed to show efficacy for this target; however, this could have been due to methodological limitations, especially in how the stimulation was delivered (99). One important methodological limitation in the study was that devices were programmed below the euphoria and hypomania threshold and patients could have been underdosed.

Two depression targets, the NAc and the superolateral MFB (slMFB), are central components of the reward system, which has been shown to be dysfunctional in depression (100). The response and remission rates of NAc are $50 \%$ and $30 \%$, respectively, at 12 months (101) and $45 \%$ and $9 \%$ at two years (102). A recent pilot study investigating the MFB target suggests that it may be part of the system for reward seeking with stimulation causing a state of positive affective excitement (103). For this small series, six out of seven patients attained the response criterion within days of stimulation activation. At last observation (12-33 weeks), six out of seven patients were responders and four were classified as remitters (see Table 4).

Depression is a heterogenous disorder that manifests with a variety of symptom constellations arising from several dysfunctional nodes (104) in one or several mood networks that is/are dysfunctional (105). DBS studies targeting the SCC (21), internal capsule $(97)$, and the reward circuitry $(28,101)$ have shown efficacy in not only severe unipolar depression, but also in individuals with bipolar disorder that were in an extended depressive episode (88). It is also clear that efficacy will increase when programming settings (96), the lead position in relation to the relevant circuitry (106), and the exact microstructural targets of modulation (93) are optimized. Ultimately, the DBS target choice for an individual's depression may be selected using the nature of the depressive symptoms (91) coupled with the side-effect profile and relevant comorbidities (107).

\section{Table 3}

Summary of studies of OCD DBS including VCNS DBS and STN DBS

\begin{tabular}{|c|c|c|c|c|c|}
\hline Study & No. patients & Response rate & $\mathrm{F} / \mathrm{u}$ & DBS target & Outcome summary \\
\hline $\begin{array}{l}\text { Huff } 2010 \text { (ref. 110) } \\
\text { improved; }\end{array}$ & 10 & $8 / 10(80 \%)$ & $12 \mathrm{mo}$ & Unil NAc & YBOCS, HDRS, and GAF significantly \\
\hline Abelson 2005 (ref. 112) & 4 & $2 / 4(50 \%)$ & $4-23$ mo & Bil ant limb IC & $\begin{array}{l}\text { HARS improved, but NS } \\
\text { YBOCS, HARS, HDRS, } \\
\text { and GAF improved; no data about }\end{array}$ \\
\hline \multicolumn{6}{|l|}{ significance } \\
\hline Greenberg 2006 (ref. 113) & 8 & $6 / 8(75 \%)$ & $36 \mathrm{mo}$ & Bil VC/VS & $\begin{array}{l}\text { YBOCS, HARS, HDRS, } \\
\text { and GAF significantly improved }\end{array}$ \\
\hline Goodman 2010 (ref. 167) & 6 & $4 / 6(66.67 \%)$ & $12 \mathrm{mo}$ & Bil VC/VS & $\begin{array}{c}\text { YBOCS an } \\
\text { HARS significantly improved }\end{array}$ \\
\hline Denys 2010 (ref. 168) & 16 & $9 / 16(56.25 \%)$ & $12 \mathrm{mo}$ & Bil NAc & $\begin{array}{l}\text { YBOCS, HARS } \\
\text { and HDRS significantly improved }\end{array}$ \\
\hline Jimenez-Ponce 2009 (ref. 114) & 5 & $5 / 5(100 \%)$ & $12 \mathrm{mo}$ & Bil inf thal & $\begin{array}{l}\text { YBOCS, HARS, HDRS, } \\
\text { and GAF significantly improved }\end{array}$ \\
\hline Greenberg 2010 (ref. 107) & 26 & $19 / 26(73.1 \%)$ & $36 \mathrm{mo}$ & Bil VC/VS & $\begin{array}{c}\text { YBOCS and } \\
\text { GAF significantly improved }\end{array}$ \\
\hline Chabardès 2012 (ref. 108) & 4 & $4 / 4(100 \%)$ & $6 \mathrm{mo}$ & Bil STN & $\begin{array}{l}\text { YBOCS improved; } \\
\text { no data about significance }\end{array}$ \\
\hline Mallet 2008 (ref. 115) & 16 & $14 / 16(87.5 \%)$ & $3 \mathrm{mo}$ & Bil STN & $\begin{array}{c}\text { YBOCS and GAF significantly improved } \\
\text { HDRS improved, but NS }\end{array}$ \\
\hline
\end{tabular}

Unil, unilateral; Bil, bilateral; ant limb IC, anterior limb of the internal capsule; inf thal, inferior thalamic peduncle; GAF, global assessment of function. 
Table 4

Summary of studies of depression DBS including NAc, VC/VS DBS and SCC DBS

\begin{tabular}{|c|c|c|c|c|c|c|}
\hline Study & F/u & HDRS & MADRS & GAF & $\begin{array}{l}\text { Clinical global } \\
\text { impression }\end{array}$ & HAMA \\
\hline Bewernick 2012 (ref. 102) & $24 \mathrm{mo}$ & $\begin{array}{l}\text { Improved } \\
\text { significantly }\end{array}$ & $\begin{array}{l}\text { Improved } \\
\text { significantly }\end{array}$ & No data & No data & $\begin{array}{l}\text { Improved } \\
\text { significantly }\end{array}$ \\
\hline Malone $2009 / 2010$ (refs. 97 and 98) & $12 \mathrm{mo}$ & $\begin{array}{l}\text { Improved } \\
\text { significantly }\end{array}$ & $\begin{array}{l}\text { Improved } \\
\text { significantly }\end{array}$ & $\begin{array}{l}\text { Improved } \\
\text { significantly }\end{array}$ & No data & No data \\
\hline Holtzheimer 2012 (ref. 88) & $24 \mathrm{mo}$ & $\begin{array}{l}\text { Improved } \\
\text { significantly }\end{array}$ & No data & $\begin{array}{l}\text { Improved } \\
\text { significantly }\end{array}$ & No data & No data \\
\hline Lozano 2012 (ref. 92) & $12 \mathrm{mo}$ & $\begin{array}{l}\text { Improved } \\
\text { significantly }\end{array}$ & No data & No data & $\begin{array}{l}\text { Improved } \\
\text { significantly }\end{array}$ & No data \\
\hline Lozano 2008 (ref. 16) & $12 \mathrm{mo}$ & $\begin{array}{l}\text { Improved } \\
\text { significantly }\end{array}$ & No data & No data & $\begin{array}{l}\text { Improved } \\
\text { significantly }\end{array}$ & No data \\
\hline
\end{tabular}

$O C D$. OCD affects $2 \%-3 \%$ of the population and is characterized by obsessions, which have been defined as recurrent unwanted ideas, images, or impulses, and compulsions, which have been defined as repetitive, stereotyped behaviors or mental acts that are often performed with the intention of neutralizing anxiety induced by obsessions. The variability of OCD symptoms mirrors its heterogeneity with respect to the response of the syndrome to conventional treatments such as CBT and medication. Following conventional treatment, $20 \%-40 \%$ of patients with OCD remain severely disabled. DBS has become an option for treatment-refractory OCD patients (108) initially through clinical studies, then through a HDE. To date, there is still a need for a large, randomized controlled trial to determine the effectiveness of DBS in OCD (109).

Several targets have been explored for OCD DBS including the NAc $(110,111)$, ALIC (112), VC/VS region $(27,107,113)$, the ITP $(114)$, and the STN $(108,115)$. An early study investigating ALIC as a potential target demonstrated a response rate of $50 \%$ in 4 patients (112). Two studies have examined unilateral (110) and bilateral (111) NAc DBS, reporting response rates of $80 \%(n=10)$ and $56 \%(n=16)$, respectively. The VC/VS region has been electrically interrogated to determine the downstream effects of such stimulation (116). For OCD, the VC/VS target has the most data and has been shown to have similar efficacy between groups with a $61.5 \%$ response (>35\% reduction in YBOCS) (107) in a worldwide, pooled study. STN DBS for OCD has also been reported as a potential target. Two studies, with 16 and 5 subjects, respectively, demonstrated response rates of $87.5 \%$ (115) and 100\% (108), where response was defined as greater than $25 \%$ improvement on the YBOCS in the Mallet study (115) which is lower than the usual response criteria (ref. 116 and see Table 3 ).

The next critical step in the advancement of this work is to hone in on the exact regions that are involved in the pathogenesis of $\operatorname{OCD}(117,118)$. A combination of structural and functional imaging prior to and after implantation could potentially provide additional insight required to identify specific elements, which would allow for enhanced efficacy $(119,120)$. All of the DBS targets appear to exert their effects at least in part by altering activity in the orbital frontal cortex (OFC), anterior cingulate cortex (ACC), and striatum (121). OCD DBS alters neural firing patterns, information transmission, and coherence between different regions in the network (121). In the future, target selection may be guided by a combination of the major symptom dimensions and by neuroanatomical subtypes discovered on detailed neuroimaging $(122,123)$. Optimization of lead position is evolving, and better results have been observed when ALIC and VC/VS electrodes were moved closer to the junction of the anterior capsule and the anterior commissure (107). Enrollment of more patients through trials instead of utilization of the HDE would allow further data collection (109).

\section{Positive and negative effects of DBS}

Positive neuropsychiatric effects from DBS of "motoric targets." Initial signals that DBS may be an intervention for psychiatric conditions came from changes that resulted from implanting in the motor circuitry (124). These unintended improvements have shaped later inquiries into new diseases and neuroanatomical targets $(125,126)$. Patients implanted in the GPi for PD and tardive dyskinesia have reported improvements in mood $(127,128)$, and patients with comorbid PD and OCD have also had improvements in anxiety with STN DBS $(125,129)$. Some TS patients implanted in the CM thalamus unexpectedly demonstrated reductions in OCD and depression symptoms (65). STN DBS for PD has been shown to improve alertness in some cohorts (130). Limbic improvements from intended motor targets may be the result of crossstimulation of nearby circuits, or alternatively, limbic-motor connections (125). The positive limbic and motoric benefits observed from a single DBS field may also be produced as a disease-specific effect (131) where microstructural differences in the basal ganglia and limbic circuits may allow for a traditionally "limbic" target to modulate motor circuitry (ref. 132; see Table 5).

Negative neuropsychiatric effects from DBS of "motoric targets." While motoric stimulation has shown some positive effects, several negative effects have also been identified. STN DBS may adversely affect cognitive and limbic circuitry in some cases (124). A case reported by Stefurak in 2003 illustrates the dissociation of mood and motor circuitry in STN DBS where a female patient with STN DBS would have voltage-dependent crying after turning on the stimulator and would stop when the stimulator was turned off (133). De novo impulse control disorder (134), mania (135), increased anger (136), worsening apathy (137), fatigue (138), cognitive decline (55), binge eating (139), worsening depression (124), de novo psychosis (124), and suicidality (140) all appear to be uncommon, but possible effects. While verbal fluency has been shown to be affected in STN DBS, 
Table 5

Positive/negative neuropsychiatric effects from motoric/limbic DBS

\begin{tabular}{|c|c|c|c|}
\hline Study & Symptom & Effect & Comments \\
\hline Kosel et al. 2007^ (ref. 127) & Depression & Improvement & Case report with 1 patient \\
\hline Damier et al. 2007A (ref. 128) & Depression & Improvement in 1 of 10 & \\
\hline Fontaine et al. 2004 (ref. 125) & OCD & improvement & Case report with 1 patient \\
\hline \multirow[t]{3}{*}{ Okun 2009 (ref. 53) } & Happy mood & Increase & NS \\
\hline & Sad mood & Decrease & NS \\
\hline & Tense mood & Increase & NS \\
\hline Graff-Radford 2010 (ref. 169) & Tense mood & Decrease & Significant \\
\hline \multirow[t]{3}{*}{ Moum 2012 (ref. 134) } & ICD & Resolved in 2 and appeared de novo in 2 & 2 out of 6 patients for both \\
\hline & DDS & no change & \\
\hline & Both & no change & \\
\hline Chopra 2012 (ref. 135) & Mania & Resolved & 12 out of 14 patients \\
\hline Kluger 2012 (ref. 138) & Fatigue & $58 \%$ of patients & \\
\hline \multirow[t]{2}{*}{ Voon 2008 (ref. 140) } & Suicidal ideation & $0.45 \%(24 / 5311)$ after DBS & \\
\hline & Suicide attempt & $0.90 \%(48 / 5311)$ after DBS & \\
\hline \multirow[t]{2}{*}{ Zahodne 2011 (ref. 139) } & Binge eating & Increased & \\
\hline & Subthreshold BED & increased & \\
\hline \multirow[t]{2}{*}{ Burdick 2011 (ref. 136) } & Anger & $\begin{array}{l}\text { Increased after STN, GPi; } \\
\text { decreased after VIM }\end{array}$ & \\
\hline & Confusion & Increased after GPi, decreased after VIM & \\
\hline Kirsch-Darrow 2011 (ref. 137) & Apathy & $\begin{array}{l}\text { Increased in middle aged, } \\
\text { not in older patients }\end{array}$ & \\
\hline Kuhn 2007 (ref. 148) & Alcohol abuse & Cessation & Case report with 1 patient \\
\hline Kuhn 2009 (ref. 170) & Smoking & Cessation & 3 out of 10 \\
\hline Mantione 2010 (ref. 146) & Smoking, overeating & Cessation & Case report with 1 patient \\
\hline \multirow[t]{2}{*}{ Zhou 2011 (ref. 171) } & Heroin abuse & Cessation & Case report with 1 patient \\
\hline & Smoking & Decrease & \\
\hline Valencia-Alfonso 2012 (ref. 172) & Heroin abuse & Cessation & Case report with 1 patient \\
\hline Shapira 2006 (ref. 151) & panic & $\begin{array}{l}\text { Reproducible with stimulation } \\
\text { of ventral-most contacts }\end{array}$ & Case report with 1 patient \\
\hline Haq 2010 (ref. 89) & OCD, mania & Present with specific DBS settings & Case report with 1 patient \\
\hline \multirow[t]{2}{*}{ Flaherty 2004 (ref. 173) } & Mania & High voltage in dorsal-most contacts & Case report with 1 patient \\
\hline & Depression, apathy & High voltage in ventral-most contacts & \\
\hline \multirow[t]{3}{*}{ Nuttlin 2002 (ref. 174) } & Memory function & Decrease & 1 out of 4 \\
\hline & Hypomania & Present with specific DBS settings & 2 out of 4 \\
\hline & Fear & Present with specific DBS settings & \\
\hline
\end{tabular}

ICD, impulse control disorder; DDS, dopamine dysregulation syndrome; BED, binge eating disorder; VIM, ventral intermediate nucleus of the thalamus.

it appears that GPI DBS does not have as large an effect on fluency (141). In many cases these side effects are reversible (133) and may be stimulation related (142), resolving when the DBS is turned off (133). Some of these cases may be related to lead position and stimulation parameters. Some effects (e.g. verbal fluency) may be related to the surgery itself (i.e., microlesion effect). Optimization may lead to motor and nonmotor improvements (refs. 143, 144; see Table 5).

Positive neuropsychiatric effects from DBS of "limbic based targets." The NAc target was presumed to have an antianxiety effect, and because of improvements in OCD, it was hypothesized to have an independent antidepressant effect (102). Unintended improvements for other comorbid disorders have led to expansion of the potential neuropsychiatric DBS indications. Acute changes in memory were associated with unintended stimulation of the fornix in an intervention whose intent was to stimulate the lateral hypothalamus for obesity (126). DBS in the lateral hypothalamus was ineffective for obesity in that study, but utilization of novel programming techniques demonstrated efficacy in a later study (145). NAc DBS has also resulted in weight loss, and there are some reports of improvements in recreational drug use for patients receiving this treatment for OCD (ref. 146; see Table 5). The NAc is also a potential target for the treatment of addiction (147), and patients with comorbid OCD and addiction demonstrated reductions in addictive behaviors $(148,149)$. The addiction-like behaviors that have shown improvement include alcohol intake, nicotine dependence, and opiate use $(149,150)$.

Negative neuropsychiatric effects from DBS of "limbic targets." Mania is one of the most concerning negative neuropsychiatric effects resulting from DBS (89), but paradoxical worsening of anxiety and depression has also been reported (151).Feelings of suicidality can emerge; however, it is unclear whether these feeling are the result of the stimulation itself or of an augmentation of a preimplantation suicidality. Feelings of irritability and anger have been reported $(53,136,152)$. Cognitive dysfunction at high amplitudes has been observed with BA 25 DBS along with the occurrence of paradoxical worsening of depressive symptoms (21). Limbic STN DBS for OCD has been associated with hypomania, anxiety, impulsiveness, depression symptoms, and obsessive-compulsive thoughts (ref. 152 and see Table 5). 


\section{Conclusion}

DBS is a demonstrably effective tool for modulating dysfunctional brain circuits in a variety of conditions. As a therapy, it resides at an interface between functional neurosurgery, movement disorder neurology, and interventional psychiatry (153). DBS has not only been shown to improve several symptoms within a variety of neuropsychiatric disorders, but also to improve quality of life (154). We must remain cautious and careful as we expand DBS into neuropsychiatric diseases. Numerous articles have called for greater oversight of these technologies to prevent misuse (109). Ethical criteria for the use of DBS will be critical as the field moves forward $(155,156)$. The concern for an individual's decisional capacity $(157)$ and therapeutic misconceptions (158) are important and relevant concerns. A call has been made for a registry for psychiatric DBS implantations (159) and for more forums dedicated to reducing poor outcomes in psychiatric DBS (160). The leaders in the field for these emerging technologies have authored guidelines, but more information on each target is needed (161). Additionally, a structured psychotherapeutic rehabilitation process post-DBS may be useful in addressing subsequent difficulties in reintegrating into society (i.e., TS DBS) (162). All of these efforts will help to improve and refine DBS therapy (163) and help us to avoid repeating the mistakes of the era of psychosurgery (164).

\section{Acknowledgments}

We would like to acknowledge support from the National Parkinson Foundation Center of Excellence. We also acknowledge NIDA training grant R25 DA020537.

Address correspondence to: Michael S. Okun, 3450 Hull Road, 4th Floor, Gainesville, Florida 32607, USA. Phone: 352.294.5400; Fax:; E-mail: okun@neurology.ufl.edu.
1. Meyer FC, Chemali Z. On education: teaching the neurology-psychiatry interface using a flexible quadrant model [published online ahead of print 2013]. Clinical Neuropsychiatry. Epub code: CN100004

2. Benabid AL. What the future holds for deep brain stimulation. Expert Rev Med Devices. 2007; 4(6):895-903.

3. Lozano AM, Lipsman N. Probing and regulating dysfunctional circuits using deep brain stimulation. Neuron. 2013;77(3):406-424.

4. FDA approves humanitarian device exemption for deep brain stimulator for severe obsessivecompulsive disorder [press release]. February 19, 2009. http://www.fda.gov/NewsEvents/ Newsroom/PressAnnouncements/ucm 149529 htm. FDA Web site. Updated April 18, 2013 Accessed September 13, 2013.

5. Benabid AL, et al. Deep brain stimulation: BCI at large, where are we going to? Prog Brain Res. 2011; 194:71-82

6. Ferrao YA, DinizJB, Lopes AC, Shavitt RG, Greenberg $\mathrm{B}$, Miguel E. [Resistance and refractoriness in obsessive-compulsive disorder]. Rev Bras Psiquiatr. 2007; 29(suppl 2):S66-S76.

7. Giacobbe P, Mayberg HS, Lozano AM. Treatment resistant depression as a failure of brain homeostatic mechanisms: implications for deep brain stimulation. Exp Neurol. 2009;219(1):44-52.

8. Sackeim HA. The definition and meaning of treatment-resistant depression. J Clin Psychiatry. 2001; 62(suppl 16):10-17.

9. Denny AP, Behari M. Motor fluctuations in Parkinson's disease. J Neurol Sci. 1999;165(1):18-23.

10. Abudy A, Juven-Wetzler A, Zohar J. Pharmacological management of treatment-resistant obsessive-compulsive disorder. CNS Drugs. 2011;25(7):585-596.

11. Porta M, Sassi M, Menghetti C, Servello D. The need for a proper definition of a "treatment refractoriness" in Tourette syndrome. Front Integr Neurosci. 2011;5:22

12. Mink JW, et al. Patient selection and assessment recommendations for deep brain stimulation in Tourette syndrome. Mov Disord. 2006 21(11):1831-1838

13. Defer GL, Widner H, Marie RM, Remy P, Levivier $\mathrm{M}$. Core assessment program for surgical interventional therapies in Parkinson's disease (CAPSITPD). Mov Disord. 1999;14(4):572-584.

14. Greenberg BD, et al. Neurosurgery for intractable obsessive-compulsive disorder and depression: critical issues. Neurosurg Clin NAm. 2003;14(2):199-212.

15. Gaynes BN, Rush AJ, Trivedi MH, Wisniewski SR, Spencer D, Fava M. The STAR*D study: treating depression in the real world. Cleve Clin J Med. 2008; 75(1):57-66

16. Lozano AM, Mayberg HS, Giacobbe P, Hamani C,
Craddock RC, Kennedy SH. Subcallosal cingulate gyrus deep brain stimulation for treatment-resistant depression. Biol Psychiatry. 2008;64(6):461-467.

17. Okun MS, et al. Do stable patients with a premorbid depression history have a worse outcome after deep brain stimulation for Parkinson disease? Neurosurgery. 2011;69(2):357-360

18. Bernal-Pacheco O, et al. Taking a better history for behavioral issues pre- and post-deep brain stimulation: issues missed by standardized scales. Neuromodulation. 2012;16(1):35-39.

19. Houeto JL, et al. Subthalamic stimulation in Parkinson disease: intraoperative predictive factors. Arch Neurol. 2003;60(5):690-694.

20. Sauleau $P$, et al. Motor and non motor effects during intraoperative subthalamic stimulation for Parkinson's disease. J Neurol. 2005;252(4):457-464.

21. Mayberg HS, et al. Deep brain stimulation for treatment-resistant depression. Neuron. 2005; 45(5):651-660.

22. Okun MS, et al. What's in a "smile?" Intra-operative observations of contralateral smiles induced by deep brain stimulation. Neurocase. 2004;10(4):271-279.

23. Haq IU, et al. Smile and laughter induction and intraoperative predictors of response to deep brain stimulation for obsessive-compulsive disorder. Neuroimage. 2011;54(suppl 1):S247-S255.

24. Stewart CD, Eljamel S. Prediction of implantable pulse generator longevity in deep brain stimulation: limitations and possible solutions in clinical practice. Stereotact Funct Neurosurg. 2011;89(5):299-304.

25. Tykocki T, Nauman P, Koziara H, Mandat T. Microlesion effect as a predictor of the effectiveness of subthalamic deep brain stimulation for Parkinson's disease. Stereotact Funct Neurosurg. 2013; 91(1):12-17.

26. Hardesty DE, Sackeim HA. Deep brain stimulation in movement and psychiatric disorders. Biol Psychiatry. 2007;61(7):831-835

27. Goodman WK, et al. Deep brain stimulation for intractable obsessive compulsive disorder: pilot study using a blinded, staggered-onset design. Biol Psychiatry. 2010;67(6):535-542.

28. Schlaepfer TE, Bewernick BH, Kayser S, Mädler B, Coenen VA. Rapid effects of deep brain stimulation for treatment-resistant major depression. Biol Psychiatry. 2013;73(12):1204-1212.

29. Burdick AP, et al. Prevalence of Twiddler's syndrome as a cause of deep brain stimulation hardware failure. Stereotact Funct Neurosurg. 2010; 88(6):353-359.

30. Montuno MA, Kohner AB, Foote KD, Okun MS. An algorithm for management of deep brain stimulation battery replacements: devising a web-based battery estimator and clinical symptom approach. Neuromodulation. 2013;16(2):147-153.
31. Wagle Shukla A, Okun MS. Personalized medicine in deep brain stimulation through utilization of neural oscillations. Neurology. 2012;78(24):1900-1901.

32. Okun MS, Foote KD. Parkinson's disease DBS: what, when, who and why? The time has come to tailor DBS targets. Expert Rev Neurother. 2010; 10(12):1847-1857.

33. Van Essen DC, Ugurbil K. The future of the human connectome. Neuroimage. 2012;62(2):1299-1310.

34. Gutman DA, Holtzheimer PE, Behrens TE, Johansen-Berg H, Mayberg HS. A tractography analysis of two deep brain stimulation white matter targets for depression. Biol Psychiatry. 2009;65(4):276-282.

35. Henderson JM. "Connectomic surgery": diffusion tensor imaging (DTI) tractography as a targeting modality for surgical modulation of neural networks. Front Integr Neurosci. 2012;6:15.

36. Coenen VA, Allert N, Mädler B. A role of diffusion tensor imaging fiber tracking in deep brain stimulation surgery: DBS of the dentato-rubrothalamic tract (drt) for the treatment of therapyrefractory tremor. Acta Neurochir (Wien). 2011; 153(8):1579-1585

37. Johansen-Berg H, et al. Anatomical connectivity of the subgenual cingulate region targeted with deep brain stimulation for treatment-resistant depression. Cereb Cortex. 2008;18(6):1374-1383.

38. Gradinaru V, Mogri M, Thompson KR, Henderson JM, Deisseroth K. Optical deconstruction of parkinsonian neural circuitry. Science. 2009; 324(5925):354-359.

39. Foutz TJ, McIntyre CC. Evaluation of novel stimulus waveforms for deep brain stimulation. J Neural Eng. 2010;7(6):066008

40. Foutz TJ, Ackermann DM, Kilgore KL, McIntyre CC. Energy efficient neural stimulation: coupling circuit design and membrane biophysics. PLoS One. 2012; 7(12):e51901

41. Chaturvedi A, Foutz TJ, McIntyre CC. Current steering to activate targeted neural pathways during deep brain stimulation of the subthalamic region. Brain Stimul. 2012;5(3):369-377.

42. Butson CR, McIntyre CC. Role of electrode design on the volume of tissue activated during deep brain stimulation. J Neural Eng. 2006;3(1):1-8.

43. Eusebio A, Cagnan H, Brown P. Does suppression of oscillatory synchronisation mediate some of the therapeutic effects of DBS in patients with Parkinson's disease? Front Integr Neurosci. 2012;6:47.

44. Broadway JM, et al. Frontal theta cordance predicts 6-month antidepressant response to subcallosal cingulate deep brain stimulation for treatmentresistant depression: a pilot study. Neuropsychopharmacology. 2012;37(7):1764-1772.

45. Maling N, Hashemiyoon R, Foote KD, Okun MS, Sanchez JC. Increased thalamic gamma band activ- 
ity correlates with symptom relief following deep brain stimulation in humans with Tourette's syndrome. PLoS One. 2012;7(9):e44215.

46. Okun MS, et al. A trial of scheduled deep brain stimulation for Tourette syndrome: moving away from continuous deep brain stimulation paradigms. JAMA Neurol. 2013;70(1):85-94.

47. Morrell MJ. Responsive cortical stimulation for the treatment of medically intractable partial epilepsy. Neurology. 2011;77(13):1295-1304.

48. Tang JK, et al. Neuronal firing rates and patterns in the globus pallidus internus of patients with cervical dystonia differ from those with Parkinson's disease. J Neurophysiol. 2007;98(2):720-729.

49. Okun MS. Deep-brain stimulation for Parkinson's disease. N Engl J Med. 2012;367(16):1529-1538.

50. Deuschl G, et al. A randomized trial of deep-brain stimulation for Parkinson's disease. NEngl JMed.2006; 355(9):896-908.

51. Williams A, et al. Deep brain stimulation plus best medical therapy versus best medical therapy alone for advanced Parkinson's disease (PD SURG trial): a randomised, open-label trial. Lancet Neurol. 2010; 9(6):581-591.

52. Schuepbach WM, et al. Neurostimulation for Parkinson's disease with early motor complications. N Engl J Med. 2013;368(7):610-622.

53. Okun MS, et al. Cognition and mood in Parkinson's disease in subthalamic nucleus versus globus pallidus interna deep brain stimulation: the COMPARE trial. Ann Neurol. 2009;65(5):586-595.

54. Follett KA, et al. Pallidal versus subthalamic deepbrain stimulation for Parkinson's disease. N EnglJ Med. 2010;362(22):2077-2091.

55. Weaver FM, et al. Randomized trial of deep brain stimulation for Parkinson disease: thirty-sixmonth outcomes. Neurology. 2012;79(1):55-65.

56 . Odekerken VJ, et al. Subthalamic nucleus versus globus pallidus bilateral deep brain stimulation for advanced Parkinson's disease (NSTAPS study): a randomised controlled trial. Lancet Neurol. 2013; 12(1):37-44

57. Oyama G, et al. GPi and STN deep brain stimulation can suppress dyskinesia in Parkinson's disease. Parkinsonism Relat Disord. 2012;18(7):814-818.

58. Rubin JE, McIntyre CC, Turner RS, Wichmann $\mathrm{T}$. Basal ganglia activity patterns in parkinsonism and computational modeling of their downstream effects. Eur J Neurosci. 2012; 36(2):2213-2228.

59. McNeely ME, et al. Effects of deep brain stimulation of dorsal versus ventral subthalamic nucleus regions on gait and balance in Parkinson's disease. J Neurol Neurosurg Psychiatry. 2011;82(11):1250-1255.

60. Moscovich M, Morishita T, Foote KD, Favilla CG, Chen ZP, Okun MS. Effect of lead trajectory on the response of essential head tremor to deep brain stimulation. Parkinsonism Relat Disord. 2013; 19(9):789-794.

61. Butson CR, Cooper SE, Henderson JM, Wolgamuth B, McIntyre CC. Probabilistic analysis of activation volumes generated during deep brain stimulation. Neuroimage. 2011;54(3):2096-2104.

62. Frankemolle AM, et al. Reversing cognitive-motor impairments in Parkinson's disease patients using a computational modelling approach to deep brain stimulation programming. Brain. 2010; 133(pt 3):746-761.

63. Maks CB, Butson CR, Walter BL, Vitek JL, McIntyre CC. Deep brain stimulation activation volumes and their association with neurophysiological mapping and therapeutic outcomes. J Neurol Newrosurg Psychiatry. 2009;80(6):659-666.

64. Brocker DT, et al. Improved efficacy of temporally non-regular deep brain stimulation in Parkinson's disease. Exp Neurol. 2013;239:60-67.

65. Porta M, et al. Thalamic deep brain stimulation for treatment-refractory Tourette syndrome: two-year outcome. Neurology. 2009;73(17):1375-1380.

66. Servello D, Porta M, Sassi M, Brambilla A, Robertson MM. Deep brain stimulation in 18 patients with severe Gilles de la Tourette syndrome refractory to treatment: the surgery and stimulation. J Neurol Neurosurg Psychiatry. 2008;79(2):136-142.

67. Piedimonte $\mathrm{F}$, et al. Behavioral and motor improvement after deep brain stimulation of the globus pallidus externus in a case of Tourette's syndrome. Neuromodulation. 2013;16(1):55-58.

68. Martinez-Torres I, Hariz MI, Zrinzo L, Foltynie T, Limousin P. Improvement of tics after subthalamic nucleus deep brain stimulation. Neurology. 2009; 72(20):1787-1789.

69. Viswanathan A, Jimenez-Shahed J, Baizabal Carvallo JF, Jankovic J. Deep brain stimulation for Tourette syndrome: target selection. Stereotact Funct Neurosurg. 2012;90(4):213-224.

70. Porta M, et al. Deep brain stimulation for treatment of refractory Tourette syndrome: long-term followup. Acta Neurochir (Wien). 2012;154(11):2029-2041.

71. Maciunas RJ, et al. Prospective randomized doubleblind trial of bilateral thalamic deep brain stimulation in adults with Tourette syndrome. J Neurosurg. 2007; 107(5):1004-1014.

72. Ackermans L, et al. Double-blind clinical trial of thalamic stimulation in patients with Tourette syndrome. Brain. 2011;134(pt 3):832-844.

73. Martinez-Fernandez R, et al. Deep brain stimulation for Gilles de la Tourette syndrome: a case series targeting subregions of the globus pallidus internus. Mov Disord. 2011;26(10):1922-1930.

74. Cannon E, Silburn P, Coyne T, O'Maley K, Crawford JD, Sachdev PS. Deep brain stimulation of anteromedial globus pallidus interna for severe Tourette's syndrome. Am J Psychiatry. 2012; 169(8):860-866.

75. Makki MI, Govindan RM, Wilson BJ, Behen ME, Chugani HT. Altered fronto-striato-thalamic connectivity in children with Tourette syndrome assessed with diffusion tensor MRI and probabilistic fiber tracking. J Child Neurol. 2009;24(6):669-678.

76. Sachdev PS, Cannon E, Coyne TJ, Silburn P. Bilateral deep brain stimulation of the nucleus accumbens for comorbid obsessive compulsive disorder and Tourette's syndrome. BMJ Case Rep. 2012; 2012.pii: bcr2012006579.

77. Saleh C, Gonzalez V, Cif L, Coubes P. Deep brain stimulation of the globus pallidus internus and Gilles de la Tourette syndrome: Toward multiple networks modulation. Surg Neurol Int. 2012; 3(suppl 2):S127-S142.

78. Welter ML, et al. Internal pallidal and thalamic stimulation in patients with Tourette syndrome. Arch Neurol. 2008;65(7):952-957.

79. Kuhn J, et al. In vivo evidence of deep brain stimulation-induced dopaminergic modulation in Tourette's syndrome. Biol Psychiatry. 2012; 71(5):e11-e13.

80. Widge AS, Moritz CT. Rodent Proof of Concept for a Patient-Controllable Brain Stimulator (Closed-Loop Limbic Prosthesis). In 2013 Society of Biological Psychiatry Meeting, San Francisco, California, USA. May 16-18, 2013

81. Oyama G, et al. Rescue leads: a salvage technique for selected patients with a suboptimal response to standard DBS therapy. Parkinsonism Relat Disord. 2011; 17(6):451-455.

82. Sturm V, et al. DBS in the basolateral amygdala improves symptoms of autism and related selfinjurious behavior: a case report and hypothesis on the pathogenesis of the disorder. Front Hum Neurosci. 2012;6:341

83. Servello D, et al. De novo and rescue DBS leads for refractory Tourette syndrome patients with severe comorbid OCD: a multiple case report. J Neurol. 2009; 256(9):1533-1539.

84. Williams N, Simpson AN, Simpson K, Nahas Z.
Relapse rates with long-term antidepressant drug therapy: a meta-analysis. Hum Psychopharmacol. 2009; 24(5):401-408.

85. Jimenez $\mathrm{F}$, et al. A patient with a resistant major depression disorder treated with deep brain stimulation in the inferior thalamic peduncle. Neurosurgery. 2005;57(3):585-593.

86. Sartorius A, et al. Remission of major depression under deep brain stimulation of the lateral habenula in a therapy-refractory patient. Biol Psychiatry. 2010; 67(2):e9-e11.

87. Drevets WC, Ongur D, Price JL. Neuroimaging abnormalities in the subgenual prefrontal cortex: implications for the pathophysiology of familial mood disorders. Mol Psychiatry. 1998;3(3):220-226.

88. Holtzheimer PE, et al. Subcallosal cingulate deep brain stimulation for treatment-resistant unipolar and bipolar depression. Arch Gen Psychiatry. 2012; 69(2):150-158.

89. Haq IU, et al. A case of mania following deep brain stimulation for obsessive compulsive disorder. Stereotact Funct Neurosurg. 2010;88(5):322-328.

90. Riva-Posse P, Holtzheimer PE, Garlow SJ, Mayberg HS. Practical considerations in the development and refinement of subcallosal cingulate white matter deep brain stimulation for the treatment resistant depression. World Neurosurg. 2012; pii:S1878-8750(12)01436-2.

91. Rizvi SK, et al. Investigation of the targeted effects of deep brain stimulation on depressive symptom profiles: a pooled analysis. Society of Biological Psychiatry 68th Annual Scientific Convention, May 16-18, 2013. San Francisco, California, USA.

92. Lozano AM, et al. A multicenter pilot study of subcallosal cingulate area deep brain stimulation for treatment-resistant depression. J Neurosurg. 2012; 116(2):315-322

93. Mayberg, H. Optimizing subcallosal cingulate DBS for treatment resistant depression. Society of Biological Psychiatry 68th Annual Scientific Convention, May 16-18, 2013. San Francisco, California, USA

94. Kennedy SH, et al. Deep brain stimulation for treatment-resistant depression: follow-up after 3 to 6 years. Am J Psychiatry. 2011;168(5):502-510.

95. Puigdemont D, et al. Deep brain stimulation of the subcallosal cingulate gyrus: further evidence in treatment-resistant major depression. Int J Neuropsychopharmacol. 2011:1-13.

96. Ramasubbu RA. Double-blind optimization of subcallosal cingulate deep brain stimulation for treatment-resistant depression: a pilot study. Society of Biological Psychiatry 68th Annual Scientific Convention, May 16-18, 2013. San Francisco, California, USA.

97. Malone DA, et al. Deep brain stimulation of the ventral capsule/ventral striatum for treatment-resistant depression. Biol Psychiatry. 2009; 65(4):267-275.

98. Malone DA. Use of deep brain stimulation in treatment-resistant depression. Cleve Clin J Med. 2010; 77(suppl 3):S77-S80.

99. Rezai A. Deep brain stimulation (DBS) for treatment-resistant depression: a randomized controlled trial. 2012 ASSFN Biennial Meeting Abstracts - Oral Presentation. June 3-6, 2012. San Francisco, California, USA.

100.Schlaepfer TE, et al. Deep brain stimulation to reward circuitry alleviates anhedonia in refractory major depression. Neuropsychopharmacology. 2008; 33(2):368-377.

101. Bewernick BH, et al. Nucleus accumbens deep brain stimulation decreases ratings of depression and anxiety in treatment-resistant depression. Biol Psychiatry. 2010;67(2):110-116.

102. Bewernick BH, Kayser S, Sturm V, Schlaepfer TE. Long-term effects of nucleus accumbens deep brain stimulation in treatment-resistant depression: evidence for sustained efficacy. Neuropsycho- 
pharmacology. 2012;37(9):1975-1985

103. Coenen VA, Panksepp J, Hurwitz TA, Urbach H, Madler B. Human medial forebrain bundle (MFB) and anterior thalamic radiation (ATR): imaging of two major subcortical pathways and the dynamic balance of opposite affects in understanding depression. J Neuropsychiatry Clin Neurosci. 2012; 24(2):223-236

104.McGrath CL, et al. Toward a neuroimaging treatment selection biomarker for major depressive disorder. JAMA Psychiatry. 2013;70(8):821-829.

105. Downar J, Daskalakis ZJ. New targets for rTMS in depression: a review of convergent evidence. Brain Stimul. 2013;6(3):231-240.

106.Lujan JL, et al. Tractography-activation models applied to subcallosal cingulate deep brain stimulation. Brain Stimul. 2013;6(5):737-739.

107. Greenberg BD, et al. Deep brain stimulation of the ventral internal capsule/ventral striatum for obsessive-compulsive disorder: worldwide experience. Mol Psychiatry. 2010;15(1):64-79.

108. Chabardes S, et al. Deep brain stimulation for obsessive-compulsive disorder: subthalamic nucleus target [published onlinea ahead of print March 30, 2012]. World Neurosurg. doi:10.1016/j. wneu.2012.03.010

109. Fins JJ, et al. Misuse of the FDA's humanitarian device exemption in deep brain stimulation for obsessive-compulsive disorder. Health Aff (Millwood). 2011;30(2):302-311.

110. Huff W, et al. Unilateral deep brain stimulation of the nucleus accumbens in patients with treatmentresistant obsessive-compulsive disorder: Outcomes after one year. Clin Neurol Neurosurg. 2010; 112(2):137-143.

111. Denys D, et al. Deep brain stimulation of the nucleus accumbens for treatment-refractory obsessivecompulsive disorder. Arch Gen Psychiatry. 2010; 67(10):1061-1068.

112. Abelson JL, et al. Deep brain stimulation for refractory obsessive-compulsive disorder. Biol Psychiatry. 2005; 57(5):510-516.

113. Greenberg BD, et al. Three-year outcomes in deep brain stimulation for highly resistant obsessivecompulsive disorder. Neuropsychopharmacology. 2006; 31(11):2384-2393.

114.Jimenez-Ponce F, et al. Preliminary study in patients with obsessive-compulsive disorder treated with electrical stimulation in the inferior thalamic peduncle. Neurosurgery. 2009; 65(6 suppl):203-209.

115. Mallet L, et al. Subthalamic nucleus stimulation in severe obsessive-compulsive disorder. $\mathrm{N}$ Engl J Med. 2008;359(20):2121-2134.

116. Mian MK, Campos M, Sheth SA, Eskandar EN. Deep brain stimulation for obsessive-compulsive disorder: past, present, and future. Neurosurg Focus. 2010;29(2):E10.

117. Burbaud P, et al. Neuronal activity correlated with checking behaviour in the subthalamic nucleus of patients with obsessive-compulsive disorder. Brain. 2013;136(pt 1):304-317.

118.Lipsman N, Neimat JS, Lozano AM. Deep brain stimulation for treatment-refractory obsessivecompulsive disorder: the search for a valid target. Neurosurgery. 2007;61(1):1-11.

119. Lujan JL, Chaturvedi A, McIntyre CC. Tracking the mechanisms of deep brain stimulation for neuropsychiatric disorders. Front Biosci. 2008;13:5892-5904.

120. Le Jeune F, et al. Decrease of prefrontal metabolism after subthalamic stimulation in obsessive-compulsive disorder: a positron emission tomography study. Biol Psychiatry. 2010;68(11):1016-1022.

121. Bourne SK, Eckhardt CA, Sheth SA, Eskandar EN. Mechanisms of deep brain stimulation for obsessive compulsive disorder: effects upon cells and circuits. Front Integr Neurosci. 2012;6:29.

122. Harrison BJ, et al. Brain corticostriatal systems and the major clinical symptom dimensions of obsessive-compulsive disorder. Biol Psychiatry. 2013; 73(4):321-328.

123.van den Heuvel OA, et al. The major symptom dimensions of obsessive-compulsive disorder are mediated by partially distinct neural systems. Brain. 2009;132(pt 4):853-868.

124. Saleh C, Okun MS. Clinical review of deep brain stimulation and its effects on limbic basal ganglia circuitry. Front Biosci. 2008;13:5708-5731.

125. Fontaine D, et al. Effect of subthalamic nucleus stimulation on obsessive-compulsive disorder in a patient with Parkinson disease. Case report. J Neurosurg. 2004;100(6):1084-1086

126. Hamani C, et al. Memory enhancement induced by hypothalamic/fornix deep brain stimulation. Ann Neurol. 2008;63(1):119-123.

127. Kosel M, et al. Mood improvement after deep brain stimulation of the internal globus pallidus for tardive dyskinesia in a patient suffering from major depression. J Psychiatr Res. 2007;41(9):801-803.

128. Damier $P$, et al. Bilateral deep brain stimulation of the globus pallidus to treat tardive dyskinesia. Arch Gen Psychiatry. 2007;64(2):170-176.

129. Mallet L, et al. Compulsions, Parkinson's disease, and stimulation. Lancet. 2002;360(9342):1302-1304.

130. Fimm B, Heber IA, Coenen VA, Fromm C, Noth J, Kronenbuerger M. Deep brain stimulation of the subthalamic nucleus improves intrinsic alertness in Parkinson's disease. Mov Disord. 2009;24(11):1613-1620.

131. Neuner I, Podoll K, Lenartz D, Sturm V, Schneider F. Deep brain stimulation in the nucleus accumbens for intractable Tourette's syndrome: followup report of 36 months. Biol Psychiatry. 2009; 65(4):e5-e6.

132. Neuner I, et al. Microstructure assessment of grey matter nuclei in adult tourette patients by diffusion tensor imaging. Neurosci Lett. 2011;487(1):22-26.

133. Stefurak T, et al. Deep brain stimulation for Parkinson's disease dissociates mood and motor circuits: a functional MRI case study. Mov Disord. 2003; 18(12):1508-1516

134. Moum SJ, et al. Effects of STN and GPi deep brain stimulation on impulse control disorders and dopamine dysregulation syndrome. PLoS One. 2012; 7(1):e29768.

135. Chopra A, et al. Underlying neurobiology and clinical correlates of mania status after subthalamic nucleus deep brain stimulation in Parkinson's disease: a review of the literature. J Neuropsychiatry Clin Neurosci. 2012;24(1):102-110.

136. Burdick AP, et al. Do patient's get angrier following STN, GPi, and thalamic deep brain stimulation. Neuroimage. 2011;54(suppl 1):S227-S232.

137. Kirsch-Darrow L, Zahodne LB, Marsiske M, Okun MS, Foote KD, Bowers D. The trajectory of apathy after deep brain stimulation: from pre-surgery to 6 months post-surgery in Parkinson's disease. Parkinsonism Relat Disord. 2011;17(3):182-188.

138. Kluger BM, et al. The prevalence of fatigue following deep brain stimulation surgery in Parkinson's disease and association with quality of life. Parkinsons Dis. 2012;2012:769506.

139. Zahodne LB, et al. Binge eating in Parkinson's disease: prevalence, correlates and the contribution of deep brain stimulation. J Neuropsychiatry Clin Neurosci. 2011;23(1):56-62.

140.Voon V, et al. A multicentre study on suicide outcomes following subthalamic stimulation for Parkinson's disease. Brain. 2008;131(pt 10):2720-2728.

141. Dietz J, et al. Stimulation region within the globus pallidus does not affect verbal fluency performance. Brain Stimul. 2013;6(3):248-253.

142. Chopra A, et al. Voltage-dependent mania after subthalamic nucleus deep brain stimulation in Parkinson's disease: a case report. Biol Psychiatry. 2011; 70(2):e5-e7.

143. Campbell MC, et al. Mood response to deep brain stimulation of the subthalamic nucleus in Parkinson's disease. J Neuropsychiatry Clin Neurosci. 2012; 24(1):28-36.

144.Okun MS, Green J, Saben R, Gross R, Foote $\mathrm{KD}$, Vitek JL. Mood changes with deep brain stimulation of STN and GPi: results of a pilot study. J Neurol Neurosurg Psychiatry. 2003; 74(11):1584-1586.

145. Whiting DM, et al. Lateral hypothalamic area deep brain stimulation for refractory obesity: a pilot study with preliminary data on safety, body weight, and energy metabolism. J Neurosurg. 2013; 119(1):56-63.

146. Mantione M, van de Brink W, Schuurman PR, Denys D. Smoking cessation and weight loss after chronic deep brain stimulation of the nucleus accumbens: therapeutic and research implications: case report. Neurosurgery. 2010;66(1):E218.

147. Voges J, Müller U, Bogerts B, Münte T, Heinze HJ. Deep brain stimulation surgery for alcohol addiction [published online ahead of print July 21, 2012]. World Neurosurg. doi:10.1016/j. wneu.2012.07.011.

148. Kuhn J, et al. Remission of alcohol dependency following deep brain stimulation of the nucleus accumbens: valuable therapeutic implications? J Neurol Neurosurg Psychiatry. 2007;78(10):1152-1153.

149. Kuhn J, et al. Deep brain stimulation of the nucleus accumbens and its usefulness in severe opioid addiction [published online ahead of print January 22, 2013]. Mol Psychiatry. doi:10.1038/mp.2012.196.

150.Müller UJ, et al. Deep brain stimulation of the nucleus accumbens for the treatment of addiction. Ann N Y Acad Sci. 2013;1282:119-128.

151.Shapira NA, et al. Panic and fear induced by deep brain stimulation. J Neurol Neurosurg Psychiatry. 2006; 77(3):410-412.

152.Kuhn J, Grundler TO, Lenartz D, Sturm V, Klosterkotter J, Huff W. Deep brain stimulation for psychiatric disorders. Dtsch Arztebl Int. 2010; 107(7):105-113.

153.Stetka BK, Kantor EM, Williams NR. A new psychiatry subspecialty? Medscape Psychiatry. May 30, 2013. http://www.medscape.com/viewarticle/ 804826. Accessed September 13, 2013.

154.Zahodne LB, et al. Greater improvement in quality of life following unilateral deep brain stimulation surgery in the globus pallidus as compared to the subthalamic nucleus. J Neurol. 2009;256(8):1321-1329.

155. Synofzik M, Schlaepfer TE. Electrodes in the brain-ethical criteria for research and treatment with deep brain stimulation for neuropsychiatric disorders. Brain Stimul. 2011;4(1):7-16.

156. Fins JJ, et al. Ethical guidance for the management of conflicts of interest for researchers, engineers and clinicians engaged in the development of therapeutic deep brain stimulation. J Neural Eng. 2011; 8(3):033001.

157. Christopher PP, Leykin Y, Appelbaum PS, Holtzheimer PE, Mayberg HS, Dunn LB. Enrolling in deep brain stimulation research for depression: influences on potential subjects' decision making. Depress Anxiety. 2012;29(2):139-146.

158. Fisher CE, et al. The ethics of research on deep brain stimulation for depression: decisional capacity and therapeutic misconception. Ann N Y Acad Sci. 2012; 1265:69-79.

159. Synofzik M, Fins JJ, Schlaepfer TE. A neuromodulation experience registry for deep brain stimulation studies in psychiatric research: rationale and recommendations for implementation. Brain Stimul. 2012;5(4):653-655.

160. Rabins P, et al. Scientific and ethical issues related to deep brain stimulation for disorders of mood, behavior, and thought. Arch Gen Psychiatry. 2009; 66(9):931-937.

161.Schlaepfer TE, George MS, Mayberg H. WFSBP Guidelines on Brain Stimulation Treatments in 
Psychiatry. World J Biol Psychiatry. 2010;11(1):2-18. 162.Riva-Posse P, Holtzheimer PE, Garlow SJ, Mayberg HS. Practical considerations in the development and refinement of subcallosal cingulate white matter deep brain stimulation for treatment resistant depression. World Neurosurg. 2012; pii:S18788750(12)01436-2.

163. Bell E, Mathieu G, Racine E. Preparing the ethical future of deep brain stimulation. Surg Neurol. 2009; 72(6):577-586.

164. Kringelbach ML, Green AL, Owen SL, Schweder PM, Aziz TZ. Sing the mind electric - principles of deep brain stimulation. Eur J Neurosci. 2010; 32(7):1070-1079.

165. Okun MS, et al. Subthalamic deep brain stimulation with a constant-current device in Parkinson's disease: an open-label randomised controlled trial. Lancet Neurol. 2012;11(2):140-149.
166. Odekerken VJ, et al. Subthalamic nucleus versus globus pallidus bilateral deep brain stimulation for advanced Parkinson's disease (NSTAPS study): a randomised controlled trial. Lancet Neurol. 2013; 12(1):37-44.

167. Goodman WK, et al. Deep brain stimulation for intractable obsessive compulsive disorder: pilot study using a blinded, staggered-onset design. Biol Psychiatry. 2010;67(6):535-542.

168. Denys D, et al. Deep brain stimulation of the nucleus accumbens for treatment-refractory obsessivecompulsive disorder. Arch Gen Psychiatry. 2010; 67(10):1061-1068.

169.Graff-Radford J, et al. Mood and motor effects of thalamic deep brain stimulation surgery for essential tremor. Eur J Neurol. 2010;17(8):1040-1046.

170.Kuhn J, et al. Observations on unaided smoking cessation after deep brain stimulation of the nucle- us accumbens. Eur Addict Res. 2009;15(4):196-201.

171.Zhou H, Xu J, Jiang J. Deep brain stimulation of nucleus accumbens on heroin-seeking behaviors: a case report. Biol Psychiatry. 2011;69(11):e41-e42.

172.Valencia-Alfonso CE, et al. Effective deep brain stimulation in heroin addiction: a case report with complementary intracranial electroencephalogram. Biol Psychiatry. 2012;71(8):e35-e37.

173. Flaherty AW, et al. Deep brain stimulation of the anterior internal capsule for the treatment of Tourette syndrome: technical case report. Neurosurgery. 2005;57(suppl 4):E403; discussion E403.

174. Nuttin B, et al. Targeting bed nucleus of the stria terminalis for severe obsessive-compulsive disorder: more unexpected lead placement in obsessive-compulsive disorder than in surgery for movement disorders. World Neurosurg. 2012; S1878-S8750(12):01463-01465. 